\title{
Selection factors of seaport type logistics center of Fujian free-trade zone
}

\author{
Dan Liu' Xiulian $\mathrm{Hu}$, ShihMing $\mathrm{Ou}$
}

Fuzhou University of International Studies and Trade, China

*Corresponding author: Dan Liu, Master, snowsugar@sina.com

\begin{abstract}
According to the characteristics of Fuzhou harbor type logistics center, using PEST analysis to find out the competitive advantages, and listed factors that have a major impact on logistics center location selection, and then uses DEMATEL analysis to establish the initial matrix, such as normalized matrix model, and draw the causality diagram. Based on the analysis results, the study figures out that geology factors and topographic factors are the largest impact elements in the whole model. The results are useful for the logistics companies to set up in Fuzhou area harbor type logistics center location choice when carries on the reasonable location planning and provide constructive suggestions.
\end{abstract} Key words: Seaport type logistics center; PEST analysis; DEMATEL analysis; Fujian Free- Trade Zone.

\section{Introduction}

Industrial development planning of China (Fujian) pilot free trade zone (Plan as below) , released in August 2015, indicates that Fujian free trade pilot zone will build regional international shipping logistics center, its volume of containers will increase to 17 million TEUs and freight throughput will reach 250 million tons.

To achieve these targets, Fujian free trade zone port group will strengthen the ability to deploy shipping resources and the shipping services, basically form a comprehensive distributing network covering the west coast of the Straits, build a modern shipping service system to promote regional shipping subject and shipping element agglomeration, strengthen cross-strait cooperation in the ports and have made significant progress in shipping logistics towards Taiwan, enhance the shipping logistics cooperation with countries along the Maritime Silk Route.

The management authority of all ports had transferred to local governments in 2002, which gave local governments more authority and impetus to develop the port economy. Qing-Cai Chen points out that port logistics has got a quick development, but due to strong competition, so the government should be a corresponding operation and infrastructure construction of the public policy support, in order to ensure the realization of the strategic purpose ${ }^{1}$. 


\section{Research methods}

The research methods used in the study are Political Economic Social and Technology (PEST)analysis and DEMATEL analysis.

\subsection{PEST analysis}

Firstly, the PEST analysis of the seaport type logistics center of Fujian Free- Trade Zone will be described as follows:

\subsubsection{Political factors:}

In August 2014, Fujian government have issued the platform for action on strengthening port development (2014-2018), pointed out that around the "three must" requirements of the provincial committee, powered by deepening reform, focusing on speeding up port construction, strengthen the planning guide.We will work hard to promote the construction of port infrastructure and the network of open channels, and strive to expand the port's hinterland and enhance the competitiveness of the port, promote the transformation and upgrading of ports, expand the function of services, promote the development of port and industry and urban interaction, deepen cooperation between Fujian and Taiwan ports, and promote the construction of the 21st century maritime silk road. The port construction of Fujian province has become a modern port group facing the world, connecting the three regions of the two sides and serving the development of the central and Midwest regions.

\subsubsection{Economic and environmental factors :}

With its close proximity to Taiwan, Fujian province is open to the outside world, and relevant industries and port economy have developed rapidly and became one of the areas of rapid economic development in China ${ }^{2}$. In the trend of economic globalization, ports play a stimulating function of the economic development of city and its surrounding areas is gradually enhanced, lingang economic has become an important driving force of port city's economic development at home and abroad. The port city economy is the effective way and important carrier of the port city to drive regional economic development and implement the strategy of urban development. It is a new economic model closely related to the development of economic and social development.

\subsubsection{Infrastructural factors:}

For seaport logistics center, transportation ability has great influence on its own development, It is connected with not only the survival and development of the logistics center, but also the economical development of the whole region. Zeng-Chuo Si (2015) mentions that the port 
economy plays a key role in the system of port infrastructure and port city economic interaction development. It is the interactive node, interface, carrier, hub and link ${ }^{3}$.

\subsubsection{Natural environmental factors :}

Fujian province is located in the southeast coast of China, belonging to the hills of Fujian and Zhejiang, the terrain is mainly hilly, the terrain is high in the northwest, the southeast is low, the coastline is zigzag, with many excellent harbors and islands. The river system is relatively developed, and the largest river in Fujian province flows through the central part of Fuzhou.

According to the study of Huaixue Xing (2010), Fujian is located in the southeast margin of the second uplift belt of the new huaxia giant tectonic system, and the fracture structure in this area is very developed, mainly in the north east and north west two directions ${ }^{4}$. The structure of the rock mass in the area is relatively simple, but since Fujian province is a strong earthquake zone, it is important to analyze the data of Fujian port before starting the logistics center, as shown in table 1.

Table1 - The index design

\begin{tabular}{|c|c|c|c|}
\hline $\begin{array}{ll}\text { First } & \text { class } \\
\text { index }\end{array}$ & $\begin{array}{l}\text { Second class } \\
\text { index }\end{array}$ & Definition of index & $\begin{array}{l}\text { Index } \\
\text { ID }\end{array}$ \\
\hline \multirow{3}{*}{$\begin{array}{l}\text { Economical } \\
\text { factors }\end{array}$} & $\begin{array}{l}\text { construction } \\
\text { cost }\end{array}$ & the construction costs of building seaport logistics center & $\mathrm{F} 1$ \\
\hline & operating cost & $\begin{array}{l}\text { All variable expenses incurred when the physical business is } \\
\text { completed include storage fee, circulation processing fee, sorting and } \\
\text { distribution fee, and related labor costs, equipment maintenance, etc }\end{array}$ & $\mathrm{F} 2$ \\
\hline & $\begin{array}{l}\text { import and } \\
\text { export sales }\end{array}$ & $\begin{array}{l}\text { The purpose of building a logistics center is to increase the sales of } \\
\text { goods in the area }\end{array}$ & F3 \\
\hline \multirow{2}{*}{$\begin{array}{l}\text { Hardware } \\
\text { and } \\
\text { infrastructure } \\
\text { factors }\end{array}$} & $\begin{array}{l}\text { logistics } \\
\text { facilities }\end{array}$ & $\begin{array}{l}\text { Including existing warehouses, distribution networks and other } \\
\text { logistics infrastructure, the informationization of logistics } \\
\text { management. }\end{array}$ & F4 \\
\hline & $\begin{array}{l}\text { traffic } \\
\text { conditions }\end{array}$ & $\begin{array}{l}\text { It must accord with the optimization of various modes of } \\
\text { transportation, so it mainly pays attention to the distribution and } \\
\text { transportation capacity of surrounding road network }\end{array}$ & F5 \\
\hline \multirow{3}{*}{$\begin{array}{l}\text { natural } \\
\text { environment } \\
\text { al factors }\end{array}$} & climatic factors & $\begin{array}{l}\text { The area should pay attention to typhoon, annual precipitation, } \\
\text { temperature and inevitable special climate }\end{array}$ & F6 \\
\hline & $\begin{array}{l}\text { orographic } \\
\text { factors }\end{array}$ & Focus on the wide area with high terrain and flat terrain & F7 \\
\hline & geology factors & $\begin{array}{l}\text { The capacity of the foundation is critical for container and facility } \\
\text { equipment. It should be ruled out unsuitable soil }\end{array}$ & F8 \\
\hline \multirow{3}{*}{$\begin{array}{l}\text { macro-enviro } \\
\text { nmental } \\
\text { factors }\end{array}$} & national policy & government policy & F9 \\
\hline & its economy & $\begin{array}{l}\text { The economic development of this city has affected the scale of the } \\
\text { regional logistics center }\end{array}$ & F10 \\
\hline & $\begin{array}{l}\text { international } \\
\text { environment }\end{array}$ & $\begin{array}{l}\text { Political and economic factors such as war and world economic crisis } \\
\text { can affect the import and export trade. }\end{array}$ & F11 \\
\hline
\end{tabular}


Table 2 - The criteria for the importance of guidelines

\begin{tabular}{|l|l|l|l|l|l|l|}
\hline \multirow{2}{*}{$\begin{array}{l}\text { Problem } \\
\text { significance }\end{array}$} & Unimportance & $\begin{array}{l}\text { Extremely low } \\
\text { importance }\end{array}$ & $\begin{array}{l}\text { low } \\
\text { importance }\end{array}$ & $\begin{array}{l}\text { Moderate } \\
\text { importance }\end{array}$ & $\begin{array}{l}\text { Highly } \\
\text { importance }\end{array}$ & $\begin{array}{l}\text { Extreme } \\
\text { importance }\end{array}$ \\
\cline { 2 - 7 } & 0 & 1 & 2 & 3 & 4 & 5 \\
\hline
\end{tabular}

\subsection{DEMATEL analysis}

This study screens a total of 11 secondary indexes: construction cost, operating cost, import and export sales, logistics facilities, traffic conditions, climatic factors, orographic factors, geology factors, national policy, its economy, international environment, etc. Based on the above indexes, this paper designs DEMATEL questionnaire, and the questionnaire design is completed directly. Before filling in the answers, we communicated with these experts and discussed the topic, and then completed the effective questionnaire.

\section{Data Analysis}

DEMATEL has been widely used by many areas.DEMATEL can be presented as follows.

\subsection{Understand the problem and define the guidelines}

Firstly to understand the problem and define the guidelines, and then learn more about the problem, list the guidelines in the system and define them.There are several steps to proceed the DEMETEL analysis and the results are presented as follows:

\subsection{Determine the degree of correlation between two factors}

A measuring criterion was designed to determine the degree of inter influence between each two factors. The grading ranges from 0 to 5 , which is divided into 6 grades, which can be used to evaluate the importance of each criterion, as shown in table 2.

When the magnitude of the impact is known, the correlation between the criteria can be expressed as a matrix. From the initial matrix, the direct relation matrix, i-x matrix, $\mathrm{i}-\mathrm{x}$ inverse matrix and the total influence relation matrix are obtained, as shown in table 3.

Suppose a $n \times n$ initial matrix $X$. Each value in the matrix $X_{i j}(i=1,2, \cdots, n ; j=1,2, \cdots$, $\mathrm{n})$, expresses the direct degree influence between factor $\mathrm{i}$ and factor $\mathrm{j}$.

$$
X=\left[\begin{array}{llll}
0 & x_{12} & \cdots & x_{1 n} \\
x_{21} & 0 & \cdots & x_{2 n} \\
\vdots & \vdots & \ddots & \vdots \\
x_{n 1} & x_{n 2} & \ldots & 0
\end{array}\right]
$$

Calculate normalized direct influence matrix $X^{k}=\left[\begin{array}{c}k \\ i j\end{array}\right](1 \leq K \leq H)$ is the matrix which 
indicates the assessments acquired from $\mathrm{H}$ experts opinions.

$$
a^{i j}=\frac{1}{H} \sum_{k=1}^{H} X_{i j}^{k}
$$

where $i=1,2, \cdots, n ; j=1,2, \cdots, n$

Mathematically, the Normalized direct influence matrix can be obtained as follows.

$$
S=\frac{1}{\max _{1 \leq i \leq n} \sum_{j=1}^{n} a_{i j}}
$$

$$
N=A \times S
$$

Based on the normalized direct relation matric $\mathrm{N}$, the total matrix $\mathrm{T}$ (direct and indirect relation matrix) can be obtained by mathematical formula (5), and I is the unit matrix.

$$
T=N(I-N)^{-1}
$$

Through the initial matrix, average matrix and regularization matrix, the total influence matrix of each index is obtained, as shown in table 3.

Table 3 - The total influence matrix

\begin{tabular}{|c|c|c|c|c|c|c|c|c|c|c|c|}
\hline Total & F1 & F2 & F3 & F4 & F5 & F6 & F7 & F8 & F9 & F10 & F11 \\
\hline F1 & 0.404925 & 0.514313 & 0.48262 & 0.492583 & 0.499961 & 0.254656 & 0.296769 & 0.281419 & 0.387659 & 0.480802 & 0.38345 \\
\hline F2 & 0.451398 & 0.373697 & 0.46048 & 0.434314 & 0.435803 & 0.231345 & 0.248174 & 0.230402 & 0.352339 & 0.445335 & 0.35237 \\
\hline F3 & 0.485934 & 0.52339 & 0.427854 & 0.466684 & 0.497011 & 0.263551 & 0.268278 & 0.241071 & 0.424761 & 0.518018 & 0.429214 \\
\hline F4 & 0.491201 & 0.508617 & 0.485385 & 0.361358 & 0.468045 & 0.241885 & 0.255806 & 0.233034 & 0.364901 & 0.469746 & 0.364989 \\
\hline F5 & 0.500561 & 0.530278 & 0.532436 & 0.470104 & 0.399163 & 0.271741 & 0.273164 & 0.249781 & 0.402443 & 0.499841 & 0.40262 \\
\hline F6 & 0.3879 & 0.401748 & 0.397803 & 0.360365 & 0.393048 & 0.168732 & 0.229449 & 0.21738 & 0.303575 & 0.376257 & 0.299349 \\
\hline F7 & 0.489981 & 0.477162 & 0.46703 & 0.434483 & 0.469913 & 0.282327 & 0.214481 & 0.281886 & 0.354722 & 0.443547 & 0.35 \\
\hline F8 & 0.460659 & 0.446449 & 0.425394 & 0.402355 & 0.432641 & 0.252228 & 0.281937 & 0.186991 & 0.342488 & 0.414485 & 0.333716 \\
\hline F9 & 0.510224 & 0.528852 & 0.561843 & 0.478987 & 0.494363 & 0.262178 & 0.271672 & 0.25569 & 0.343042 & 0.531819 & 0.452245 \\
\hline F10 & 0.481773 & 0.492164 & 0.522909 & 0.463692 & 0.466494 & 0.251019 & 0.252068 & 0.236929 & 0.400054 & 0.393218 & 0.408135 \\
\hline F11 & 0.452945 & 0.463274 & 0.51998 & 0.424278 & 0.446197 & 0.236154 & 0.240343 & 0.229696 & 0.419469 & 0.487665 & 0.311463 \\
\hline
\end{tabular}

\subsection{Calculate the degree of centrality $(D+R)$ and the degree of causality $(D-R)$}

Define as the column of total matric T, calculate the sum of every column and express as $\mathrm{r}^{i}$, as mathematical formula (6). Define c as the row of total matric T, calculate the sum of every 
row and express as $\mathrm{c}^{j}$, as mathematical formula (7),

$$
\begin{aligned}
& r=\left[\begin{array}{c}
t_{1} \\
\vdots \\
t_{n}
\end{array}\right] \quad ; \quad r_{i}=\sum_{j=1}^{n} t_{i j}(i=1,2, \ldots, n) \\
& r=\left[\begin{array}{c}
t_{1} \\
\vdots \\
t_{n}
\end{array}\right] \quad n \times 1 \quad ; \quad r_{i}=\sum_{j=1}^{n} t_{i j}(i=1,2, \ldots, n) \\
& c=\left[\begin{array}{lll}
t_{1} & \ldots & t_{n}
\end{array}\right] \quad ; \quad C_{j}=\sum_{i=1}^{n} t_{i j}(j=1,2, \ldots, n)
\end{aligned}
$$

$r_{i}$ : The sum of degree that the factor i directly and indirectly influences other factors.

$C_{j}$ : The sum of degree that the factor $\mathrm{j}$ being directly and indirectly influenced by other factors.

When $\mathrm{i}=\mathrm{j},\left({ }{ }_{i+}{ }^{C_{j}}\right)$ is called the degree of centrality , that is, the sum of the giving influence and receiving influence, the greater the value, indicating that the factor $\mathrm{i}$ is an important factor in the overall problem, $\left({ }^{r_{i_{-}} c_{j}}\right)$ is called the degree of causality, that is, the difference of the giving influence and receiving influence, if the value is positive, indicating that giving influence is lager than receiving influence, the factor $\mathrm{i}$ is biased to influence other factors, which can be classified as the cause of the whole problem; if it is negative, indicating that giving influence is smaller than receiving influence, the factor $\mathrm{i}$ is biased to be influenced by other factors, which can be classified as the result of the whole problem, as shown in table 4 .

Table 4 - The degree of centrality (D+R) and the degree of causality (D-R)

\begin{tabular}{|l|l|l|l|l|l|l|l|l|l|l|l|}
\hline $\mathrm{D}+\mathrm{R}$ & 9.596656 & 9.275603 & 9.829499 & 9.034172 & 9.534772 & 6.251423 & 7.097673 & 6.623621 & 8.786369 & 9.429185 & 8.319013 \\
\hline $\mathrm{D}-\mathrm{R}$ & -0.63834 & -1.24429 & -0.73797 & -0.54424 & -0.47051 & 0.81979 & 1.433391 & 1.335064 & 0.595462 & -0.69228 & 0.143914 \\
\hline
\end{tabular}

\subsection{Causal Diagram}

In the causal map, $(D+R)$ is the horizontal axis, (D-R) is the vertical axis. The value of horizontal axis $(D+R)$ is divided by its average value, the value of vertical axis (D-R) is divided by 0 , then the causal map is divided into four quadrants. The meaning of the four quadrants of causal map is different, the factors in the first quadrant are the core factors, which have a high degree of centrality and a high degree of causality, it is the key factor to solve the problem; the factors in the second quadrant are the driving factors, which have a low 
degree of centrality and a high degree of causality, have independence, will affect a small number of other factors; the factors in the third quadrant are independent factors, which have a high degree of centrality and a low degree of causality, have low interactivity with other factors, it is enough to separately control the factors in this area; the factors in the fourth quadrant are affected factor, which have a low degree of centrality and a low degree of causality, the factors are in urgent need of the management which is not directly to improve the factors in the third quadrant, it need to manage the factors in the first quadrant and the second quadrant first, then it can improve the factors in this region.

\subsection{Screening important criteria}

Causality diagram can assist designer makie the right decision.and select key guidelines more visually and conveniently. When the problem phenomenon changes over time, it is necessary to re-understand the problem and define the criteria.

When the value of $(D+R)$ is greater, it is indicated that the criterion is the most important to the overall evaluation criterion. The number of $(D+R)$ the criteria values above average is as show in table 5. From table5, it can be seen that the important factors of siting planning of the port logistics center are: import and export sales, construction cost, traffic conditions and its economy.

Table 5 - The degree of centrality $(\mathrm{D}+\mathrm{R})$

\begin{tabular}{|l|l|c|}
\hline Index ID & evaluative criteria & the degree of centrality (D+R) \\
\hline F3 & import and export sales & 9.829499 \\
\hline F1 & construction cost & 9.596656 \\
\hline F5 & traffic conditions & 9.534772 \\
\hline F10 & its economy & 9.429185 \\
\hline F11 & international environment & 8.319013 \\
\hline F2 & operating cost & 9.275603 \\
\hline F4 & logistics facilities & 9.034172 \\
\hline F9 & national policy & 8.786369 \\
\hline F7 & orographic factors & 7.097673 \\
\hline F8 & geology factors & 6.623621 \\
\hline F6 & climatic factors & 6.251423 \\
\hline & mean value & 8.52190869 \\
\hline
\end{tabular}

If the degree of causality (D-R) is positive indicates that the guidelines directly affect other factors. When the value is negative, it is affected by other factors. As shown in table 6 , the impacts of geology factors,orographic factors,climatic factors,national policy,international environment are active. 
Table 6 - The degree of causality (D-R)

\begin{tabular}{|l|l|c|}
\hline Index ID & evaluative criteria & the degree of causality (D-R) \\
\hline F8 & geology factors & 1.335064 \\
\hline F7 & orographic factors & 1.433391 \\
\hline F6 & climatic factors & 0.81979 \\
\hline F9 & national policy & 0.595462 \\
\hline F11 & international environment & 0.143914 \\
\hline F5 & traffic conditions & -0.47051 \\
\hline F4 & logistics facilities & -0.54424 \\
\hline F1 & construction cost & -0.63834 \\
\hline F10 & its economy & -0.69228 \\
\hline F3 & import and export sales & -0.73797 \\
\hline F2 & operating cost & -1.24429 \\
\hline
\end{tabular}

\section{Conclusions}

This paper studies the influence factors on site selection of harbour type logistics center. We collect data by literature review, experts interview and statistics,and then, use the method of DEMATEL to study the data. According to DEMATEL analysis results, we can clearly see that geology factors and topographic factors are the largest in the whole model.

For these two factors, we can take these two factors as the important factors to consider establishing the model when deciding to establish the logistics center. Second, consider whether the regional government policy supports the development of port logistics. The reference can further explore the remaining factors and combine with the actual analysis, and then the experts can be investigated to ensure the effectiveness of the study.

\section{Acknowledgment}

This paper is supported by the social and scientific planning item of Fujian province (No. FJ2015C131) and the Outstanding Youth scientific research personnel training program of Fujian province.

\section{References}

1. Qing-cai Chen, Strategic Study on what's the Role of the Government in Promoting Logistics Development of Guangzhou Port,D. Lanzhou University,2014.

2. Zeng-Chuo Si, Interaction Development Port of Infrastructure and Port City economy,J.Management Review,27 (2015) 33-43

3. Min Liu, Hui-nan Li. Analysis on Economic Development Environment of Fujian Port,J.Modern Communication,1 (2015) 41-41

4. Xing Huai-Xue, Ge Wei-Ya, Dong Zhi-Gao, Tian Fu-Jin, Assessment of Urban Geo-environmental Quality Based on GIS for Fuzhou city,J. Shanghai Geology 31 (2010) 20-23. 